\title{
FRONTIER RESEARCH IN ASTROPHYSICS \\ IN THE GRAVITATIONAL WAVE ERA - II (EXOPLANETS AND EMERGENCE OF LIFE)
}

\author{
Lola Sabau-Graziati ${ }^{1}$ and Franco Giovannelli ${ }^{2}$
}

\section{RESUMEN}

En este artículo discutimos los exoplanetas en la zona habitable de la Vía Láctea, el origen de la vida terrestre y lo que está haciendo la humanidad 'inteligente', para completar la excursión en El Puente entre el Big Bang y la Biología, que comenzó con el artículo I (Giovannelli \& Sabau-Graziati, 2020).

\section{ABSTRACT}

In this paper we will discuss exoplanets in the habitable zone of the Milky Way, the origin of terrestrial life, and what 'intelligent' humanity is doing, in order to complete the excursion on The Bridge between the Big Bang and Biology, started with the paper I (Giovannelli \& Sabau-Graziati, 2020).

Key Words: astrobiology — planets and satellites: general

\section{INTRODUCTION}

The most important questions about the possible origin of life in our Universe became a real scientific question in the last couple decades when it appeared a near certainty that other planets must orbit other stars. And yet, it could not be proven, until the early 1990's. Then, radio and optical astronomers detected small changes in stellar emission which revealed the presence of first a few, and now many, planetary systems around other stars. We call these planets "exoplanets" to distinguish them from our own solar system neighbors (http://science.nasa.gov/astrophysics/focusareas/exoplanet-exploration/).

The research of potential habitable exoplanets has been strongly supported during the last two decades. Indeed, this field of astrophysics is now probably the most exciting since the discovery of planets Earth-like could open a serious debate about the possibility of life outside of our solar system.

A deep discussion about this fundamental problem has been published by Giovannelli \& SabauGraziati $(2016 ; 2018)$ and references therein.

\section{HABITABLE ZONE IN THE MILKY WAY AND EXOPLANETS}

The presence of numerous exoplanets in the vicinity of our solar system - as detected by the Kepler

\footnotetext{
${ }^{1}$ INTA - Dpt de Cargas Utiles y Ciencias del Espacio Ctra de Ajalvir Km 4 - E 28850 Torrejón de Ardóz, Spain (sabaumd@inta.es).

${ }^{2}$ INAF - Istituto di Astrofisica e Planetologia Spaziali, Area di Ricerca di Roma-2, Via Fosso del Cavaliere, 100, I 00133 Roma, Italy (franco.giovannelli@inaf.it).
}

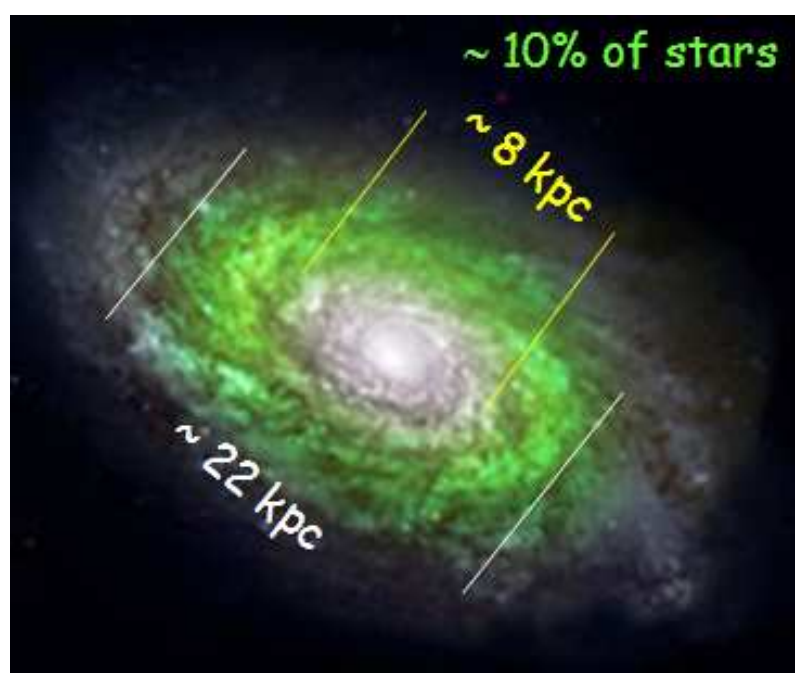

Fig. 1. Habitable zone of a Milky Way-like galaxy (Giovannelli \& Sabau-Graziati, 2016 after Lineweaver, Fenner \& Gibson, 2004).

observatory within a distance of $\approx 1 \mathrm{kpc}$ - plays an important role in speculating about the possible number of such exoplanets within the whole habitable zone (HZ) of our galaxy. Such HZ has an internal radius of $\sim 4 \mathrm{kpc}$ and an external radius of $\sim 11 \mathrm{kpc}$, as shown in Fig. 1, where the HZ in a Milky Way-like galaxy is represented in green. The number of stars contained in this zone is $\approx 10 \%$ of the total number of stars in the Galaxy. Taking into account that the thickness of the disk is $\approx 1 \mathrm{kpc}$, as evaluated by the differential rotation of the Galaxy, the habitable volume is $\sim 330 \mathrm{kpc}^{3}$. 
The Kepler observatory confirmed the detection of $\gtrsim 4000$ exoplanets within $\approx 3.3 \mathrm{kpc}^{3}$, and 30 of them Earth-size (NASA Page Last Updated: April 13, 2018). Therefore, in the HZ of our galaxy we could expect $\approx 4 \times 10^{5}$ exoplanets, with 3000 of them being Earth-sized. This is the lower limit to the number of Earth-size exoplanets in the HZ of our galaxy. Indeed, planets around other stars are the rule rather than the exception, and there are likely hundreds of billions of exoplanets in the Milky Way alone (Maruyama, Ebisuzaki \& Kurokawa, 2018). Therefore, it is evident that the probability of finding numerous habitable planets becomes very high. Next generation of instruments ground- and spacebased will provide valuable information about this intriguing problem.

A strong support on the possibility of having numerous habitable planets is coming from the discovery of the "usual" presence of water in the universe. We knew that all the water found on Earth, has been transported by small bodies such as comets and asteroids. On the contrary, the work "The ancient heritage of water ice in the solar system" (Cleeves et al., 2014) has put our knowledge one step further. It is understood that the water now present in Earth's oceans, and is present in other solar system bodies, has remained virtually unchanged with respect to that in the interstellar medium. This means that this water has not changed during the process of planet formation. This allows us to understand that the initial conditions that have favored the emergence of life are not unique, i.e. not dependent on the unique characteristics of our solar system. They can, however, be common in space.

An intriguing question about the probability of finding a number of civilization in the Galaxy arises. It is now evident that Drake's formula (Drake, 1962) must be object of a robust revision.

For years, the search for evidences of extraterrestrial civilizations has been one of humanity's most ambitious projects. Major efforts are now focused on the interception of messages from extraterrestrial civilizations, and the millimeter range is promising for these purposes (Dyson,1960). The Millimetron space observatory is aimed at conducting astronomical observations to probe a broad range of objects in the Universe in the wavelength range of $20 \mu \mathrm{m}$ to $20 \mathrm{~mm}$, including the search for extraterrestrial life (Kardashev et al., 2014, and the references therein).

\section{ORIGIN OF TERRESTRIAL LIFE}

The origin of life on Earth is one of the most intriguing fields of research because it stimulates the curiosity of the entire human race. To tackle such a research, the skills of a multitude of scientists who are experts in the various fields of research are necessary: from geology, to paleontology, to biology, to chemistry, to physics, and to the new born astrobiology.

It is our desire to venture into a short journey that gives the reader a chance to deepen the theme of the origin of life on the planet Earth and the further developments marked in a preponderant way by the presence of homo sapiens.

The Earth is 4.6 billion years old and microbial life is thought to have first appeared between 3.8 and 3.9 billion years ago; in fact, $80 \%$ of Earth's history was exclusively microbial life. Microbial life is still the dominant life form on Earth. It has been estimated that the total number of microbial cells on Earth is of the order of $2.5 \times 10^{30}$ cells, making it the major fraction of biomass on the planet.

Phylogeny refers to the evolutionary relationships between organisms. The Three Domain System, proposed by Woese (1998), is an evolutionary model of phylogeny based on differences in the sequences of nucleotides in the cell's ribosomal RNAs (rRNA), as well as the cell's membrane lipid structure and its sensitivity to antibiotics. Comparing rRNA structure is especially useful. Because rRNA molecules throughout nature carry out the same function, their structure changes very little over time. Therefore similarities and dissimilarities in rRNA nucleotide sequences are a good indication of how related or unrelated different cells and organisms are.

There are various hypotheses as to the origin of prokaryotic and eukaryotic cells. Because all cells are similar in nature, it is generally thought that all cells came from a common ancestor cell termed the Last Universal Common Ancestor (LUCA). These LUCAs eventually evolved into three different cell types, each representing a domain. The three domains are the Archaea, the Bacteria, and the Eukarya (Kaiser, 2017).

Figure 2 shows the phylogenetic tree of life (Woese, 2000; Koonin, 2014; Kaiser, 2017).

The universal phylogenetic tree not only spans all existent life, but its root and earliest branchings represent stages in the evolutionary process before modern cell types had come into being. The evolution of the cell is an interplay between vertically derived and horizontally acquired variation. Primitive cellular entities were necessarily simpler and more modular in design than modern cells are. Consequently, horizontal gene transfer early on was perva- 


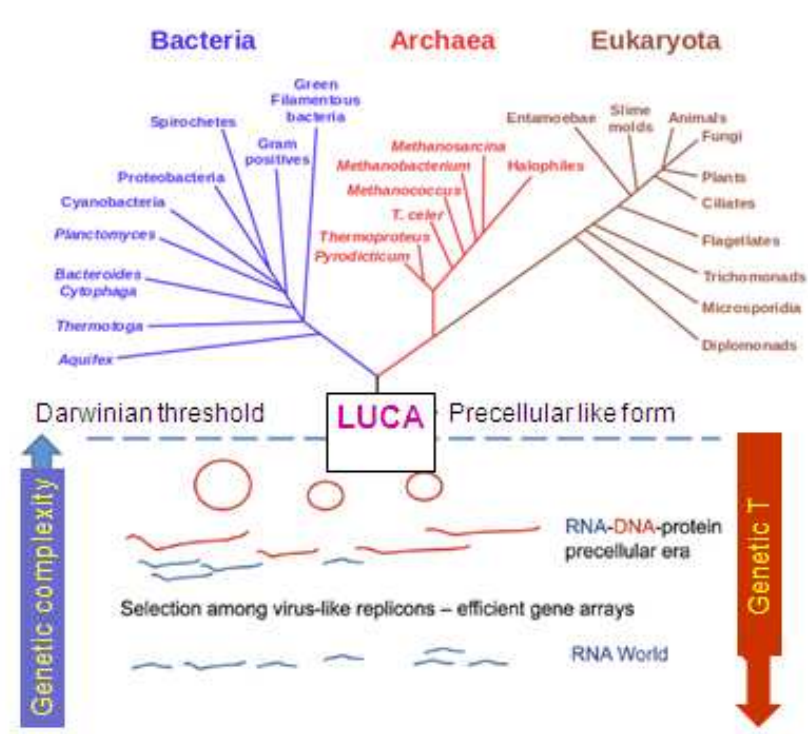

Fig. 2. The phylogenetic tree of life (adapted from Kaiser, 2017, after Woese, 2000 and Koonin, 2014).

sive, dominating the evolutionary dynamic. The root of the universal phylogenetic tree represents the first stage in cellular evolution when the evolving cell became sufficiently integrated and stable to the erosive effects of horizontal gene transfer so true organismal lineages could exist (Woese, 2000).

Woese (2002) discussed a theory for the evolution of cellular organization. As a cell design becomes more complex and interconnected a critical point is reached where a more integrated cellular organization emerges, and a vertically generated novelty can and does assume greater importance. This critical point is called the "Darwinian Threshold".

Phylogenomics and metagenomics have revealed enormous genetic and molecular diversity and a extremely high abundance of viruses and related selfish genetic elements that came across as the dominant biological entities on Earth. Furthermore, the perennial arms race between viruses and their cellular hosts is one of the defining factors of evolution. Microbial phylogenomics adds new dimensions to the fundamental picture of evolution, demonstrating that the traditional concepts based on the study of the evolution of multicellular animals and plants represent only the proverbial tip of the enormous iceberg of life's history. The scientist that made a greater contribution to this new era of evolutionary biology was Carl Woese (1928-2012; Koonin, 2014).

Following the very interesting history of the "Early Life on Earth" (Four Peaks Technologies, 2012a), we can take a short excursion on the evolution of life in our planet.
There is a general agreement that the first life on earth appeared sometime before 3.9 Gyr ago. The origins of life are known to have come after the presence of liquid water on Earth. But other than that, there is no solid evidence to pin down a more precise date. However, once large pools of water had been formed, it was possible for life to exist. There is carbon isotope evidence for life in the world's oldest known sedimentary rocks from the Isua Greenstone Belt of West Greenland estimated to be 3.85 Gyr old. These carbon rich rock layers probably accumulated as plankton bacteria on the surface, died and settled onto the ocean floor. These early life forms were not only alive, but capable of doing photosynthesis, that is inhaling carbon dioxide and exhaling oxygen. The earliest life form was very simple. It was almost certainly cyanobacteria (mistakenly called blue-green algae at times). We know it existed $3.9 \mathrm{Gyr}$ at the latest because the first life also left behind the first fossils. Assuming it took about 100 million years for life to progress to the point of photosynthesis (which is pretty sophisticated), life began at least 4.0 billion years ago. Indeed, Bell \& Harrison (2013 and the references therein) found evidence that life likely existed on earth at least $4.1 \mathrm{Gyr}$ ago. The researchers, led by Bell, studied more than 10,000 zircons searching for carbon, the key component for life. Zircons are heavy, durable minerals originally formed from molten rocks in Western Australia. They capture and preserve their immediate environment, which means that they serve as time capsules. The carbon contained in zircon has a characteristic signature, a specific ratio of ${ }^{12} \mathrm{C}$ to ${ }^{13} \mathrm{C}$, that indicates the presence of photo-synthetic life. They identified 656 zircons containing dark specks and closely analyzed 79 of them using a technique that shows the molecular and chemical structure of ancient micro-organisms in three dimensions. One of the 79 zircons contained graphite, which is pure carbon, in two locations. The graphite is older than the zircon containing it. They know the zircon is 4.1 Gyr old based on a concordant age of Uranium to Lead decay. They do not know how much older the graphite is (Bell et al., 2015a,b).

Much life on Earth belongs to the eukaryote family, all the way from blue-green algae to human beings. All multicellular organisms are eukaryotes, including animals, plants and fungi. On a numerical count basis, eukaryotes represent a tiny minority of all living things. Even in the human body, there are 10 times more microbe prokaryotes than human cells. It is believed that certain cyanobacteria evolved into blue-green algae eukaryotes about 2.5 Gyr ago, so 
much, much later than when cyanobacteria first appeared. The origin of the eukaryotic cell is considered a milestone in the evolution of life since they include all complex cells and almost all multicellular organisms. It was the development of the nucleus, which allowed highly complex forms of life to eventually evolve.

Stromatolites are the longest living form of life on the planet. They can be traced back at least 3.5 Gyr. Current marine stromatolites are only several thousand years old and can be found in waters in Western Australia and the Bahamas. Stromatolites are rock-like objects formed in shallow waters by living single celled micro-organisms, cyanobacteria, bound together in successive layers of carbonate sediment grains. Cyanobacteria come in population densities of over 3 billion organisms per square meter. Each cyanobacteria cell secretes a sticky film of mucus that traps local sediment grains. The sediment grains are bound together by the mucus and the cyanobacteria then grows over the grains. The bacteria are mobile and they photosynthesize, so they move towards light from the Sun. Because the cyanobacteria need sunlight to photosynthesize, the stromatolites are generally found in water less than $200 \mathrm{~cm}$ deep where there is considerable sunlight. Their mobility also allows them to keep up with the growing sediment layers. The first records of stromatolites began about 3.5 Gyr ago. Their presence indicates that even at such an early age, advanced prokaryotes were present, indicating that life on earth could have began much earlier, maybe as early as 4.0 byr. Stromatolites peaked about 1.25 Gyr and then began to decline. Today's marine stromatolites can be found only in isolated areas like Shark Bay, Australia and the Bahamas. As an example of their decline, at Lake Clifton in Western Australia, scientists are witnessing algae (eukaryotes) out competing cyanobacteria, caused by an increase in nutrient levels in the water (Moore \& Burne, 1994; Couradeau et al., 2011).

The first multicelled organisms are believed to have been red algae, which appeared sometime between 1.4 and 1.2 Gyr ago. This was about two billion years after stromatolites first appeared. Thus, more than one-half the time that life has been present on Earth, it was occupied by only single cell organisms.

Ancient micro-fossils of red algae were preserved and have been found on Somerset Island in northern arctic Canada. These fossils are as old as 1.2 Gyr. The first multicellular organisms had certain characteristics that have defined all complex life forms ever since. Red algae invented sex and reproduced sexually. The male red algae release sperm into the water which floats nearby coming into contact with the female's reproductive organ and fertilization occurs. Upon contact, the barriers dissolve inside of the female's reproductive organs. The male nucleus divides and one-half merges with the female nucleus. The female develops a large bulb which eventually buds off from the rest of the algae. This bulb is essentially a juvenile red alga which needs only time and nutrients to grow to an adult.

Sexual reproduction using egg and sperm cells is characteristic of multicelled organisms and first appeared in red algae. This development allowed much more complex life forms (including humans) to eventually evolve. So if you go back far enough, we all have red algae to thank for our existence.

\subsection{The Cambrian explosion}

In the book "The Cambrian Explosion: The Construction of Animal Biodiversity", Erwin \& Valentine (2013) describe the Cambrian Period, which records one of the most extraordinary transitions in the history of life. In this book the authors synthesize research from many fields to explain why there was such a remarkable novelty of animal forms. This book is an integrative work of the highest quality, covering one of the most fascinating and transformative periods in life's history.

The Cambrian Period (541-485 Myr ago) witnessed a wild explosion of new life forms. Along with new burrowing lifestyles hard body parts like shells and spines first appeared. Hard body parts allowed animals to more drastically engineer their environments, such as digging burrows. A shift also occurred towards more active animals, with defined heads and tails for directional movement to chase the prey. Active feeding by well-armored animals like trilobites may have further disrupted the sea floor that the soft Ediacaran creatures had lived on.

Trilobites were the dominant species during this period. Trilobites are extinct arthropods, animals with a hard skin shell and jointed legs. Trilobites were distant relatives of modern lobsters and horseshoe crabs. Trilobites had three (tri-lobe) segmented, rather flat, top plated bodies. They could curl up into balls for protection in seas that were increasingly filled with predators. Trilobites were the first animals to develop eyes. Trilobites came in many varieties and sizes. Their length was of $\approx 10-70 \mathrm{~cm}$. Trilobites proved to be among the most successful and enduring of all prehistoric animals. More than 17,000 species are known to have 
existed and they survived for approximately $300 \mathrm{Myr}$ and then perished. A dramatic lowering of sea levels at the time probably contributed to their demise.

A dominant animal of the Cambrian Period was the giant anomalocaris, which trapped its prey with two claw-tipped appendages lined with hooks in the front of its mouth. Anomalocaris, which means abnormal shrimp, had true compound eyes. For the time in which it lived, the anomalocaris was a gigantic creature reaching lengths of up to $\approx 200$ $\mathrm{cm}$. Anomalocaris was a free-swimming animal that undulated through the water by flexing its body like a modern dolphin. They fed on trilobites and other arthropods, worms and mollusks. Anomalocaris was the largest and most fearsome predator of the Cambrian Period. Sponges also grew in the Cambrian seas. These animals belong to the phylum "porifera" because of all the tiny pores in their bodies. One species of sponge from this period had many branches that made it look like a tree. Another type of sponge looked like an ice cream cone without the ice cream. Many of the sponges became extinct when water temperatures dropped at the end of the Cambrian period. The Cambrian Period ended with a mass extinction. The leading theory is that a period of continental glaciation occurred when the climate of the Earth cooled at the end of the Cambrian. It was suggested that the cold conditions wiped out much of the warm water organisms because they were cold intolerant. Advancing glaciers would have lowered the temperature and the levels of the shallow seas where so many marine species lived. Changes in the temperature and also the reduction of the amount of oxygen in the water would have meant the end for many species that could not readily adapt. The loss of their habitat and the increased competition among the remaining displaced species led to the demise of many of them - a truly mass extinction.

The diversification of animals that occurred over a geologically short period (the Cambrian explosion) is commonly believed that was triggered by an increase of atmospheric oxygen. However, a causal relationship between the Cambrian explosion and increasing atmospheric oxygen lacks of a convincing evidence.

Indeed, Hammarlund, von Stedingk \& Påhlman (2018) challenge that view. They start with the fact that hypoxia $\left(<1-3 \% \mathrm{O}_{2}\right)$ maintains cellular immaturity (stemness), whereas adult stem cells continuously - and paradoxically - regenerate animal tissue in oxygenated settings. Novel insights from tumour biology give insights into how cell stemness neverthe- less can be achieved through the action of oxygensensing transcription factors in oxygenated, regenerating tissue. They suggest that these hypoxiainducible transcription factors provided animals with unprecedented control over cell stemness that allowed them to cope with fluctuating oxygen concentrations. Thus, a refinement of the cellular hypoxiaresponse machinery enabled cell stemness at toxic conditions and, then, animals to evolve into the toxic realm. This view on the onset of animal diversification is consistent with geological evidence and provides a new perspective on the challenges and evolution of multicellular life.

\subsection{The evolution of humans}

Following the very interesting history of the "Early Humans" (Four Peaks Technologies, 2012b), we can take a short excursion on the evolution of humans on our planet.

While hunting for fossils in the Afar Triangle in Ethiopia, in November 1974, paleo-anthropologist Donald Johanson and graduate student Tom Gray stumbled upon the partial remains of a previously unknown species of an ape-like hominid.

The mysterious skeleton (nicknamed Lucy) was eventually classified as a 3.2 Myr old "Australopithecus afarensis" - one of humankind's earliest ancestors. The headline grabbing find filled in crucial gaps in the human family tree.

Her large pelvic opening suggested she was female, and wear on her wisdom teeth hinted she was probably around 20 years old when she died. She would have appeared more ape-like than human, with long arms and a protruding belly. Unlike knuckle dragging apes, however, the structure of her bones showed that she yet walked erect (Lieberman, 2012), and her brain was tiny (Johanson \& Maitland, 1981).

Indeed, until 1995, the fossil record suggested that there was only one pre-human species at any given time before $3 \mathrm{Myr}$ ago. It was thought that each species gave rise to another new species through time in a linear manner. But the discovery of Australopithecus bahrelghazali from Chad in 1995 and Kenyanthropus platyops from Kenya in 2001 challenged this idea. These two species were not widely accepted, and instead considered as geographic variants of Lucy's species, i.e. Australopithecus afarensis.

The discovery of a 3.4 Myr old Burtele partial foot from the Woranso-Mille announced by HaileSelassie in 2012 was the first conclusive evidence that another early human ancestor species lived alongside Australopithecus afarensis. 
The Woranso-Mille paleontological study area in Ethiopia's Afar region reveals that there were at least two, if not three, early human species living at the same time and in close geographic proximity.

This key research site has yielded new and unexpected evidence indicating that there were multiple species with different locomotor and dietary adaptations.

How did multiple closely related species manage to co-exist in a relatively small area? How did they partition the available resources? These new discoveries keep expanding our knowledge and, at the same time, raise more questions about human origins.

The fourth species was identified as Australopithecus deyiremeda, a 3.5 to $3.3 \mathrm{Myr}$ old human ancestor species from Ethiopia (Haile-Selassie et al., 2015).

Beall (2016) reports in his article a summary of the evolution of the primates:

- 55 Myr ago - First primitive primates evolve;

- 15 Myr ago - Hominidae (great apes) evolve from the ancestors of the gibbon;

- 8 Myr ago - First gorillas evolve. Later, chimp and human lineages diverge;

- 5.5 Myr ago - Ardipithecus, early "protohuman" shares traits with chimps and gorillas;

- 4 Myr ago - Ape like early humans, the Australopithecines appeared. They had brains no larger than a chimpanzee's but other more human like features;

- 3.9-2.9 Myr ago - Australoipithecus afarensis lived in Africa;

- 2.7 Myr ago - Paranthropus, lived in woods and had massive jaws for chewing;

- 2.3 Myr ago - Homo habilis first thought to have appeared in Africa

- 1.85 Myr ago - First "modern" hand emerges;

- 1.8 Myr ago - Homo ergaster begins to appear in fossil record;

- 1.6 Myr ago - Hand axes become the first major technological innovation;

- 0.8 Myr ago - Early humans control fire and create hearths. Brain size increases rapidly;

- 0.4 Myr ago - Neanderthals first begin to appear and spread across Europe and Asia;
- $0.2 \mathrm{Myr}$ ago - Homo sapiens - modern humans - appear in Africa;

- 0.04 Myr ago - Modern humans reach Europe.

A recent paper by Du et al. (2018) demonstrates that pattern and process in hominid's brain size evolution are scale-dependent. Their findings provide a quantitative basis for developing and testing scaleexplicit hypotheses about the factors that led brain size to increase during hominid evolution.

Cappellini et al. (2018) in their review conclude that studies of ancient biomolecules have come a long way-from retrieval of short sequences of mitochondrial DNA from late Holocene materials to the assembly of full nuclear genome sequences and characterization of proteins and lipids dating back millions of years. These studies have profoundly deepened our understanding of the origin of early life forms, adaptation and extinction processes, and past migrations and admixtures that gave rise to present-day biological diversity, including in our own species. Today, ancient biomolecules can provide direct insights into both the deep and recent evolutionary past, at a scale and level of detail that few would have predicted less than a decade ago.

\subsection{What intelligent humanity is doing?}

A short but important paper about The Future of Human Longevity: A Demographer's Perspective appeared in Science many years ago (Wilmoth, 1998). One of the greatest achievements of modern civilization has been the enormous reduction in human mortality. Life expectancy at birth, among early humans, was likely about 20 to 30 years (Preston, 1995). By 1900, the average length of life in industrialized nations had doubled relative to this historical extreme. Around the year 2000, life expectancy at birth was around 80 years in Japan and a few other countries, and its rise continues unabated. In recent decades, the populations of developed countries have grown considerably older, because of increasing survival to older ages as well as smaller numbers of births. Consequently, both legislators and the general public have begun to consider society's role in the support of this ever-expanding elderly population. In this new demographic context, questions about the future of human longevity have acquired a special significance for public policy and fiscal planning. Wilmoth (1998) discussed such a problem that is now extremely important for the future of the humanity.

An important book about Life Span: Evolutionary, Ecological, and Demographic Perspectives has been published by Carey \& Tuljapurkar (2003). 


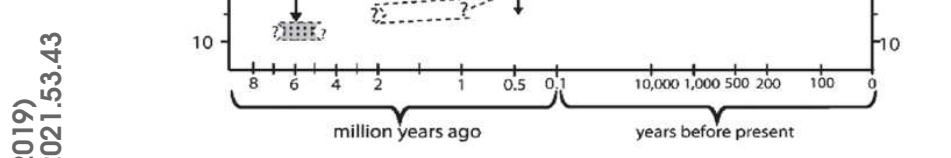

Fig. 3. The evolution of the human life expectancy (Adopted from Finch, 2012).

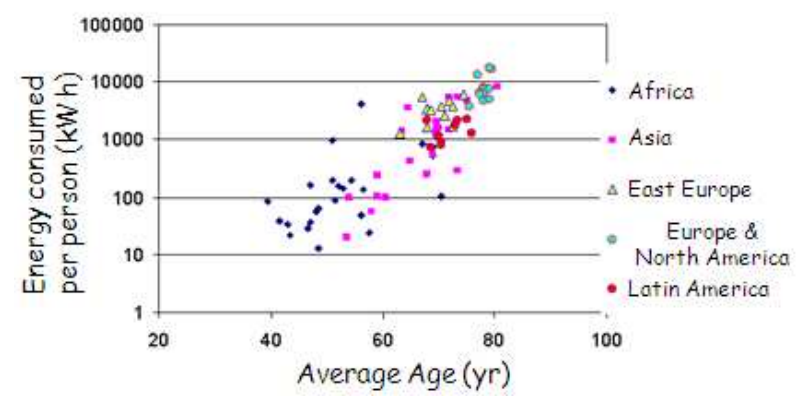

Fig. 4. The average-life in years of populations belong to different continents versus the energy consumed pro capita in kWh (Adapted from Paolo Saraceno, 2009).

The volume is concerned with the biodemography of life span, a subject that has recently emerged at the confluence of demography and biology. Over the twentieth century, human life span measured as period life expectancy has increased by more than $50 \%$ in most industrialized countries, driving concern about the benefits and costs of longer life and raising keen interest in whether we can maintain the past rate of increase of life' span. Biodemography brings together methods, materials, theories, and analyses from both biology and demography with the aim of understanding the past and anticipating the future of life span.

Without any doubt, life expectancy has grown considerably from prehistory to today. Figure 3 shows this evolution (Finch, 2012). The average life of population is directly proportional to the energy consumed pro capita as shown in Fig. 4 (Saraceno, 2009).

Estimates of the world population extended up to 2300 bring a wave of optimism to the future of humanity. In fact, in the hypothesis that humanity does not self-destruct, we could reach a decrease in the world population, for the benefit of the health of

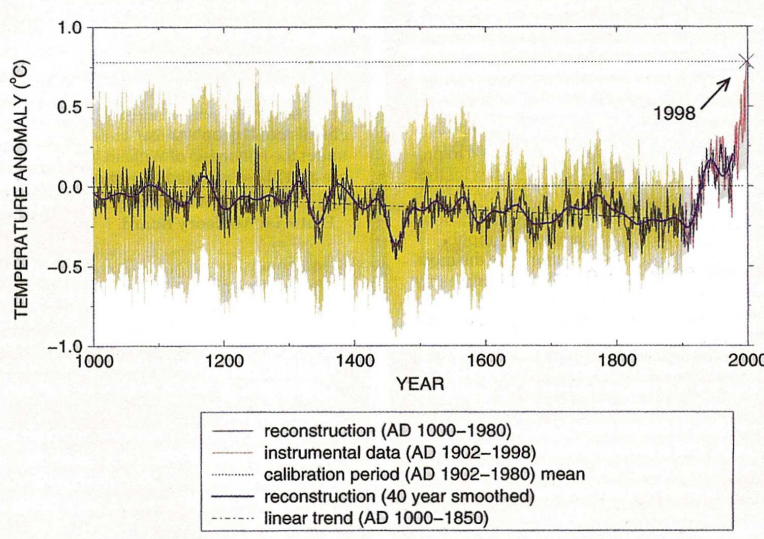

Fig. 5. The temperature of the Earth from the year 1000 A.C. (adopted from Saraceno, 2012).

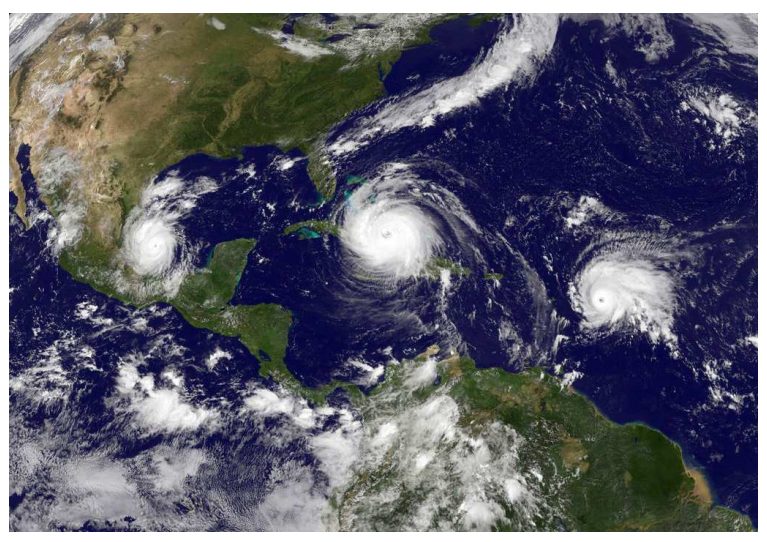

Fig. 6. On Sept. 8, 2017 three storms threatened land: from left, Tropical Storm Katia, Hurricane Irma and Tropical Storm Jose, which would intensify into a hurricane (Adopted from Astor, 2017 - Credit: NOAA/NASA GOES Project).

the planet, but only if we arrive to a more equitable distribution of wealth. This is the crucial point!

But unfortunately, the alarms of an imminent disaster are there for all to see. The temperature of the planet is increasing dramatically, as shown in Fig. 5 (Saraceno, 2012), and this can cause irreparable damage to the survival of the human species and beyond.

Indeed, for instance, the 2017 Hurricane Season Really Is More Intense Than Normal, like shown in Fig. 6. There have been 13 named storms in 2017. Only four other seasons since 1995 have had that many by Sept. 18. Just two more by the end of the year would put 2017 in the top 15 since 1851, when reliable records begin (Astor, 2017).

The winds of such hurricanes are extremely high, e.g.: Harvey $\left(\mathrm{v}_{\max }=215 \mathrm{~km} / \mathrm{h}\right)$, Irma $\left(\mathrm{v}_{\max }=\right.$ 


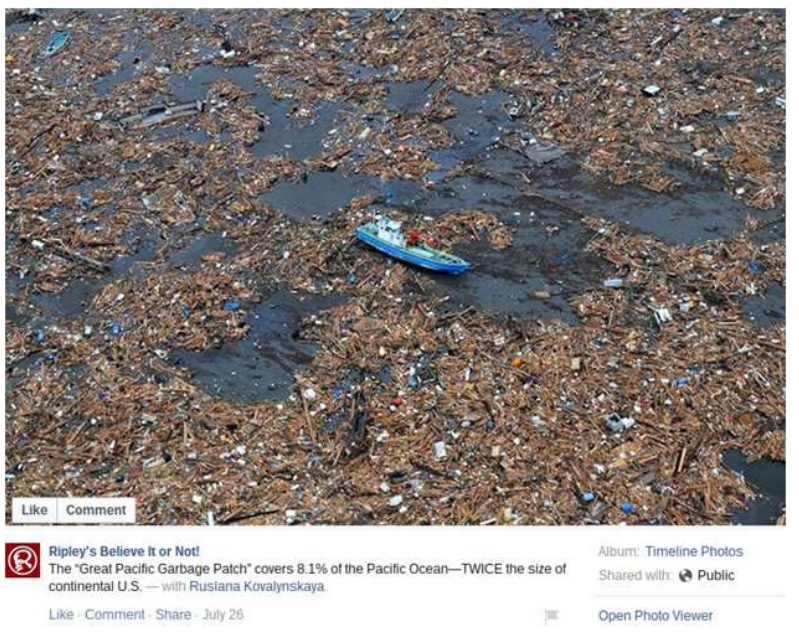

\section{Space debris}

Orbital debris, any man-made, nonfunctional object orbiting Earth, is cluttering space and can sometimes cause trouble.

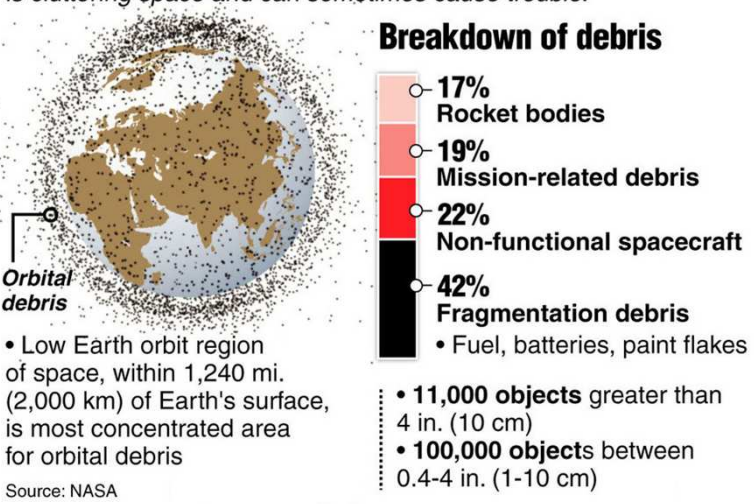

Fig. 7. Left panel: The Great Pacific Garbage Patch covers $\sim 8.1 \%$ of the Pacific ocean. Right panel: Space debris divided for the origin and size (Credit: NASA).

$285 \mathrm{~km} / \mathrm{h})$, Jose $\left(\mathrm{v}_{\max }=250 \mathrm{~km} / \mathrm{h}\right)$, Maria $\left(\mathrm{v}_{\max }=\right.$ $280 \mathrm{~km} / \mathrm{h}$ ), and the tropical storm Katia $\left(\mathrm{v}_{\max }=\right.$ $120 \mathrm{~km} / \mathrm{h}$; Wikipedia, 2017). It is superfluous to remind that the energy is proportional to $\mathrm{v}_{\max }^{2} ! ! !$ And the most important effects are evaluated in the provoked "damage" in U.S. dollars, without admitting that the effects of such hurricanes are son of the "stupidity" of humans!!!

In this regard, see the article by Giora Shaviv (2016). He discusses the phenomenon called Global Warming or in the new name Climate Change that refers to the behavior of the 'Temperature of the Earth' as a function of time. The 'Temperature of the Earth' is a complicated term as it is measured in different locations and one has to define at what location and how to average the temperature over the complicated surface of the Earth so as to obtain a single number. The atmosphere, or better said the troposphere, can be considered as a boundary layer. However, this layer is not isothermal and shows large temporal and location temperature variations. The conclusions are not given because the problem is so complicated that the numerous theoretical models lead to significantly different results from each other.

Moreover, humans are polluting the whole planet, and even the space around: a huge, swirling pile of trash in the Pacific Ocean is growing faster than expected and is now three times the size of France. Our trash harms the deepest fish in the ocean. Humans have produced 18.2 trillion pounds of plastic since the 50s. That is equal in size to 1 billion elephants (Rice, 2019), and the production of space debris is now becoming outside control (see Fig. 7 left and right panels, respectively).
The risk is that someone in the future will look at our species as we look at that of the dinosaurs!

Then, if we look for "Intelligent Lives" in the universe .... Why we should look for those like us? (Giovannelli, 2001b).

\section{CONCLUSIONS}

In the section about the Habitable Zone in the Milky Way and Exoplanets we briefly commented the fundamental problem about the research of life in the Universe. With this new-born field of science we could finally prove that the "Bridge between the Big Bang and Biology" (Giovannelli, 2001a) is, not only obviously existing, but really can be traveled over.

Indeed, we are going to study $\sim 50,000$ Clusters of Galaxies (Thomas Boller, 2017), and we have millions more. We know now more than 4000 planets clearly recognized in the Milky Way (Mullally et al., 2015). We know the lower limit of the extrapolated number of Earth-like planets in the habitable zone of our Galaxy that is $\approx 133 \times 10^{6}$. Thus we can dare to say that we are approaching to the philosophical results obtained by two great free thinkers:

- Siddhartha Gautama also known as Shakyamuni (the sage of Shaka - between the VI and V century B.C.) who exposes a grandious vision of the universe: through the concept of "major system of worlds", a concept on huge scale that implies both the existence of countless galaxies and the possibility of sentient life on other planets other than our own (from the Lotus Sutra - the central text of Mahayana Buddhism). 


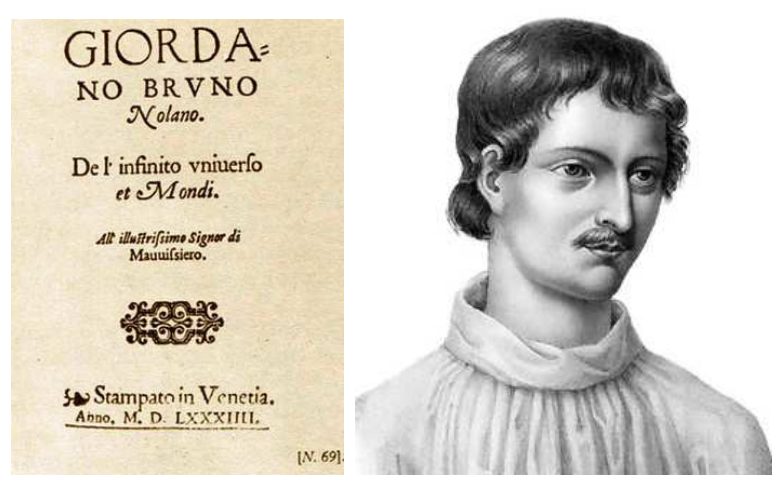

Fig. 8. Left panel: Frontispiece of the original publication of De l'infinito, universo et mondi (Giordano Bruno, 1584). Right panel: Giordano Bruno (Rixner \& Siber, 1824).

- About 2000 years later, Giordano Bruno (Nola 1548 - Roma 17th February 1600) who was burned alive in Campo dei Fiori by the "Saint Inquisition" because of his thought - summarized in De l'infinito, universo e mondi (Giordano Bruno, 1584; see Fig. 8) - that produced the same conclusions of Siddharta: The Universe is infinite and is populated by a myriad of worlds. Moreover he was saying that "Whether we like it or not, we are the cause of ourselves. Being born in this world, we fall into the illusion of the senses: we believe in what appears. We ignore that we are blind and deaf. Then the fear attacks us and we forget that we are "divine". We can change the course of events".

These philosophical thoughts were not exactly in agreement with the position of the Roman (Catholic) Church!

Of course we must wait scientific confirmation for the "alien life". We must wait even more for the discovery of "intelligent life". But, the number of discovered planets is growing very fast. Thus, we can reasonably affirm that the Universe is full of life, hoping to avoid to be burned alive like Giordano Bruno.

In the section Origin of terrestrial life and subsections we have discussed briefly the history of the emergence of life on the Earth, with particular emphasis about the behaviour of the humanity that for the first time in the history of the planet is able to provoke an artificial extinction.

The risk is that someone in the future will look at our species as we look at that of the dinosaurs!

Then, if we look for "Intelligent Lives" in the universe .... Why we should look for those like us? (Giovannelli, 2001b).

As we discussed in our paper I (Giovannelli \& Sabau-Graziati, 2020) we can state that the Universe is interconnected in all its components: from cosmic network, to clusters of galaxies, to galaxies, to stars, to planets, to living beings, up to the simple bacterium. Therefore even every manifestation of life on our planet is subject to interconnection with all the surrounding environment. We can affirm that the whole Universe is a vital whole interconnected with more or less strong links between the various components, but that certainly exist.

Luisi and Capra (2014) discussed, in their excellent book, a new systemic conception of life, which shows an interesting convergence with this paper and paper I. Indeed, new emphasis has been given to complexity, networks, and patterns of organization leading to a novel kind of 'systemic' thinking. This book integrates the ideas, models, and theories underlying the systems view of life into a single coherent framework. Taking a broad sweep through history and across scientific disciplines, the authors examine the appearance of key concepts such as autopoiesis (Maturana Romesín \& Varela García, 1972, 1980), dissipative structures, social networks, and a systemic understanding of evolution. The implications of the systems view of life for health care, management, and our global ecological and economic crises are also discussed. It is an essential reading for graduate students and researchers interested in understanding the new systemic conception of life and its implications for a broad range of professions from economics and politics to medicine, psychology and law ... and physics.

Acknowledgments: This research has made use of "The NASA's Astrophysics Data System".

\section{REFERENCES}

Astor, M. 2017, online at https://www.nytimes.com/ 2017/09/19/us/hurricanes-irma-harvey-maria. html

Beall, A. 2016, Article For Mailonline, Published: 15:03 BST, 7 June 2016 - Updated: 16:22 BST, 7 June 2016 Bell, E. A. \& Harrison, T. M. 2013, E\&PSL, 364, 1

Bell, E. A., Boehnke, P., Harrison, T. M., \& Mao, W. L. 2015a, PNAS, 112, 47

Bell, E. A., et al. 2015b, LITHOS, 234, 15

Boller, T. 2017, Talk at the Frascati Workshop 2017, Multifrequency Behaviour of High Energy Cosmic Source - XII

Bruno Giordano Nolano. 1584, De l'infinito, universo et mondi, Stampato in Venezia, Anno MDLXXXIV, in 
Dialoghi filosofici italiani, a cura di Michele Ciliberto, Mondadori, Milano (2000)

Cappellini, E., et al. 2018, ARBCh, 87, 1029. Online at https://doi.org/10.1146/ annurev-biochem-062917-012002

Carey, J. R. \& Tuljapurkar, S. 2003, Life Span: Evolutionary, Ecological, and Demographic Perspectives, Population and Development Review, A Supplement to Volume 29, 308, Population Council, New York

Cleeves, L. I., et al. 2014, Sci, 345, 6204, 1590

Couradeau, E., et al. 2011, PLoS ONE, 6, 12, e28767, pp. $1-16$

Drake, F. D. 1962, Intelligent Life in Space, New York: Macmillan, 128

Du, A., et al. 2018, in Hominin brain size evolution are scale-dependent, Proc. R. Soc. B 285: 20172738. http://dx.doi.org/10.1098/rspb.2017.2738

Dyson, F. 1960, Science, 131, 1667

Erwin, D. \& Valentine, J. 2013, The Cambrian Explosion: The Construction of Animal Biodiversity, Published January 18 th by W. H. Freeman

Finch, C. E. 2012, Proc of the American Philosophical Soc. 156,9

Four Peaks Technologies, Scottsdale, AZ. 2012a, http: \\www.earlyearthcentral.com/early\_life\ _page.html

2012b, http://www . earlyearthcentral. com/human \_page.html

Giovannelli, F. 2001a, The bridge between the big bang and biology: stars, planetary systems, atmospheres, volcanoes: their link to life, ed. Giovannelli, F., CNR: President's Bureau of the CNR, Mario Apice (General Coordinator), 1

2001b, The bridge between the big bang and biology: stars, planetary systems, atmospheres, volcanoes: their link to life, ed. Giovannelli, F., CNR: President's Bureau of the CNR, Mario Apice (General Coordinator), 439

Giovannelli, F. \& Sabau-Graziati, L. 2016, Frontier Research in Astrophysics II, Online at https://pos. sissa.it/cgi-bin/reader/conf . cgi? confid=269, id. 1

2018, Frontier Research in Astrophysics -III, online at https://pos.sissa.it/cgi-bin/ chairman/chlist. cgi?confid=331, id. 001 2021, RMxAC, 53, 225

Haile-Selassie, Y., Saylor, B. Z., Deino, A., et al. 2012, Natur, 483, 565

Haile-Selassie, Y., Gibert, L., Melillo, S. M., et al. 2015, Natur, 521, 483

Hammarlund, E. U., von Stedingk, K., \& Påhlman, S. 2018, Nature Ecology \& Evolution, 2, 220, DOI:
$10.1038 / \mathrm{s} 41559-017-0410-5$

Johanson, D. \& Maitland E. 1981, Lucy: The Beginnings of Humankind, ISBN 0-671-25036-1, New York: Simon and Schuster

Kaiser, G. 2017, in 1.3: Classification - The Three Domain System, https://bio.libretexts.org/

Kardashev, N. S., et al. 2014, PhyU, 57, 1199

Koonin, E. V. 2014, in Carl Woese special issue, www. landesbioscience.com, rNa Biology 11:3, 197

Lieberman, D. E. 2012, Natur, 483, 550

Lineweaver, C. H., Fenner, Y., \& Gibson, B. K. 2004, Science 303, 59

Luisi, P. L. \& Capra, F. 2014, The systems View of Life, Cambridge Univ. Press, 510

Maruyama, S., Ebisuzaki, T., \& Kurokawa, K. 2018, in Frontier Research in Astrophysics -III, online at https://pos.sissa.it/cgi-bin/chairman/ chlist. cgi? confid=331, id. 071

Maturana Romesín, H. \& Varela García, F. J. 1972, De Máquinas y Seres Vivos (Autopoiesis: La Organización de lo Vivo), Editorial Universitaria S. A., Chile

Maturana Romesín, H. \& Varela García, F. J. 1980, Autopoiesis and Cognition - The Realization of the Living, D. Reidel Publishing Company Dordrecth, Holland

Moore, L. S. \& Burne, R. V. 1994, in Phanerozoic Stromatolites II, ed. Bertrand-Safati, J. \& Monty, C., Crown Copyright, Netherlands, 3

Mullally, F., et al. 2015, ApJS, 217, 31

Preston, S. H. 1995, in The State of Humanity, J. L. Simon (Ed.), Blackwell, Cambridge, 30

Rice, D. 2019, in Lansing State Journal, Updated 9:35 PM EST Dec 11, 2019

Rixner, T. A. \& Siber, T. 1824, Leben und Lehrmeinungen berühmter Physiker, Sulzbach, Heft 5

Saraceno, P. 2009, Talk at Physics Dpt, La Sapienza University, Roma, Italy Energia e Ambiente: i numeri che contano

Saraceno, P. 2012, Beyond the Stars: Our Origins and the Search for Life in the Universe, World Scientific Publishing Co. Pte. Ltd

Shaviv, G. 2016, in Accretion Processes in Cosmic Sources, Online at http://pos.sissa.it/cgi-bin/ reader/conf . cgi ? confid $=288$, id. 60

Wikipedia. 2017, online at https://en.wikipedia. org/wiki/Timeline \_of \_the \_2017\_Atlantic\ _hurricane ${ }_{-}$season

Wilmoth, J. R. 1998, Sci, 280, 395

Woese, C. R. 1998, PNAS, 95, 6854

2000, PNAS, 97, 8392

2002, PNAS, 99, 8742 